\title{
Ventral sculpting decompression: a novel bone scalpel-based technique in thoracic ventral stenosis/kyphosis with myelopathy
}

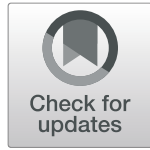

\author{
Ajay Krishnan ${ }^{1,2,3^{*}}$ D, Sameer Patil ${ }^{1}$, Chaitanya Reddy ${ }^{1}$, Shivanand Mayi ${ }^{1}$, Devanand Degulmadi ${ }^{1}$, \\ Ravi Ranjan Rai ${ }^{1}$ and Bharat R. Dave ${ }^{1}$
}

\begin{abstract}
Background: Thoracic kyphosis is not so uncommon, which presents with devastating myelopathy. In the past, the surgical treatment for it had been somewhat controversial. Traditionally, it had been addressed by open decompression and stabilization with significant dissection and disruption of normal tissues and complications.

Main body: Recently, correction techniques have evolved as the standard of care. A substantial body of evidence now supports the benefits of correction but can be questioned in view of the fact that upper dorsal kyphosis is never a cosmetic concern in our part of the world. New technique has reduced complications, but it is not solely due to the technique but due to accessory gadgets like O-arm, navigation, and IONM making it safer. We describe a method of $360^{\circ}$ decompression alone with the use of an Ultrasonic Bone Scalpel (UBS) that preserves maximum bony stability and achieves an optimum bone sculpting that negates the need for correction.
\end{abstract}

Conclusion: This technique of ventral sculpting decompression in the thoracic spine may be more utilized in the future to be applied for more wider indications.

Keywords: Thoracic, Gibbus, Kyphosis, Myelopathy, Ultrasonic Bone Scalpel

\section{Background}

Congenital abnormalities, infection, and metabolic disorders lead to bone weakness making vertebral bodies vulnerable to collapse and progressive kyphosis leading to gibbus deformities [1, 2]. Progressive kyphosis risks cord compression leading to myelopathy and paraplegia if left untreated [3]. Ossified posterior longitudinal ligament (OPLL) and multiple ossified discs also cause cord compression resulting in neurologic deficit. In severe rigid dorsal kyphosis with neurological involvement, decompression and correction of the deformity are proposed as standard care [4-8].

\footnotetext{
* Correspondence: drajaykrishnan@gmail.com

${ }^{1}$ Stavya Spine Hospital \& Research Institute, Nr Nagari Hospital, Mithakhali,

Ellisbridge, Ahmedabad, Gujarat 380006, India

²BIMS Hospital, Opp.Sir T Hospital, Charan Boarding, Jail Rd, Bhavnagar,

Gujarat 364001, India

Full list of author information is available at the end of the article
}

In cases of upper dorsal congenital rigid kyphosis, deformity correction as one of the aims of the treatment can be questioned where deformity is concealed and unnoticed for years. Often, such patients present late with neurology being the only concern. For such cases, only decompression without any attempt of deformity correction should be considered and given paramount importance [9].

Anterior decompression through a posterior-only approach can be done by the classic method explained by Ohtsuka et al. [10]. The technique was modified by many authors to reduce intraoperative complications $[8$, 11]. Presently, burr is the standard instrument used for anterior decompression through posterior-only approaches as described in the literature [10]. Also, sparse literature is available about the use of UBS for osteotomy procedures [12-14].

\section{Springer Open}

(c) The Author(s). 2020 Open Access This article is licensed under a Creative Commons Attribution 4.0 International License, which permits use, sharing, adaptation, distribution and reproduction in any medium or format, as long as you give appropriate credit to the original author(s) and the source, provide a link to the Creative Commons licence, and indicate if changes were made. The images or other third party material in this article are included in the article's Creative Commons licence, unless indicated otherwise in a credit line to the material. If material is not included in the article's Creative Commons licence and your intended use is not permitted by statutory regulation or exceeds the permitted use, you will need to obtain permission directly from the copyright holder. To view a copy of this licence, visit http://creativecommons.org/licenses/by/4.0/. 
We are presenting a technique for $360^{\circ}$ decompression of the cord through a posterior-only approach using UBS. This can be used for any pathology leading to anterior compression where only decompression is the aim of the treatment.

\section{Main text \\ Surgical procedure \\ Positioning}

The procedure was performed under general total intravenous anesthesia with intraoperative neuromonitoring (IONM). The patient was placed prone over with bolsters in an accommodative kyphotic position with adequate padding for bony prominences. Particular attention was paid and care was taken to prevent hyperextension of the neck and pressure on the eyes and abdomen. Local anesthetic infiltration was done.

\section{Exposure and pedicle screw insertion}

Midline exposure was done two vertebral levels above and below the apex of deformity for the index case (Fig. 1). Sub-periosteal dissection was completed as far as the transverse process to obtain adequate exposure on both sides. Only those facets were exposed carefully which were in the planned fusion mass. Pedicular screws were inserted in D2 and D6 using an intraoperative 3D imaging system [O-arm ${ }^{\mathrm{TM}} 1000$ year 2006, Medtronic, USA] along with a navigation system [Stealth Station ${ }^{\mathrm{TM}}$ 8 ] and connected with a temporary rod on the right side. D3 to D5 laminectomy was performed with UBS [Misonix Bone Scalpel by Misonix, Farmingdale, NY, USA].

Exposure was extended on the left side with a perpendicular incision at the level of deformity till the angle of the ribs, i.e., $12 \mathrm{~cm}$ and muscle layer was cut in a horizontal orientation (Fig. 2). Medial 3 in. of 3 ribs at the level of deformity were removed with the Ultrasonic Bone Scalpel after dislocating from the costo-transverse and costovertebral joints, respectively. The transverse process of D4 and D5 with pedicle and facets was removed with UBS. D3 and D4 nerve roots were ligatured, transfixed, and cut with the long thread left behind. Left lateral margins of the affected vertebral bodies were exposed sub-periostealy and an extra-cavitatory plane created.

\section{Osteotomy}

The upper and lower extent of needed decompression was assessed on preoperative computed tomography (CT) scan films. Clinically, a Penfield dissector was used to feel the non-compressed cerebro-spinal fluid (CSF) and the manipulable cushioned cord above and below the gibbus. Also, $\mathrm{O}$-arm-acquired images coupled with the navigation probe were used (Fig. 2). The defined level laminectomy

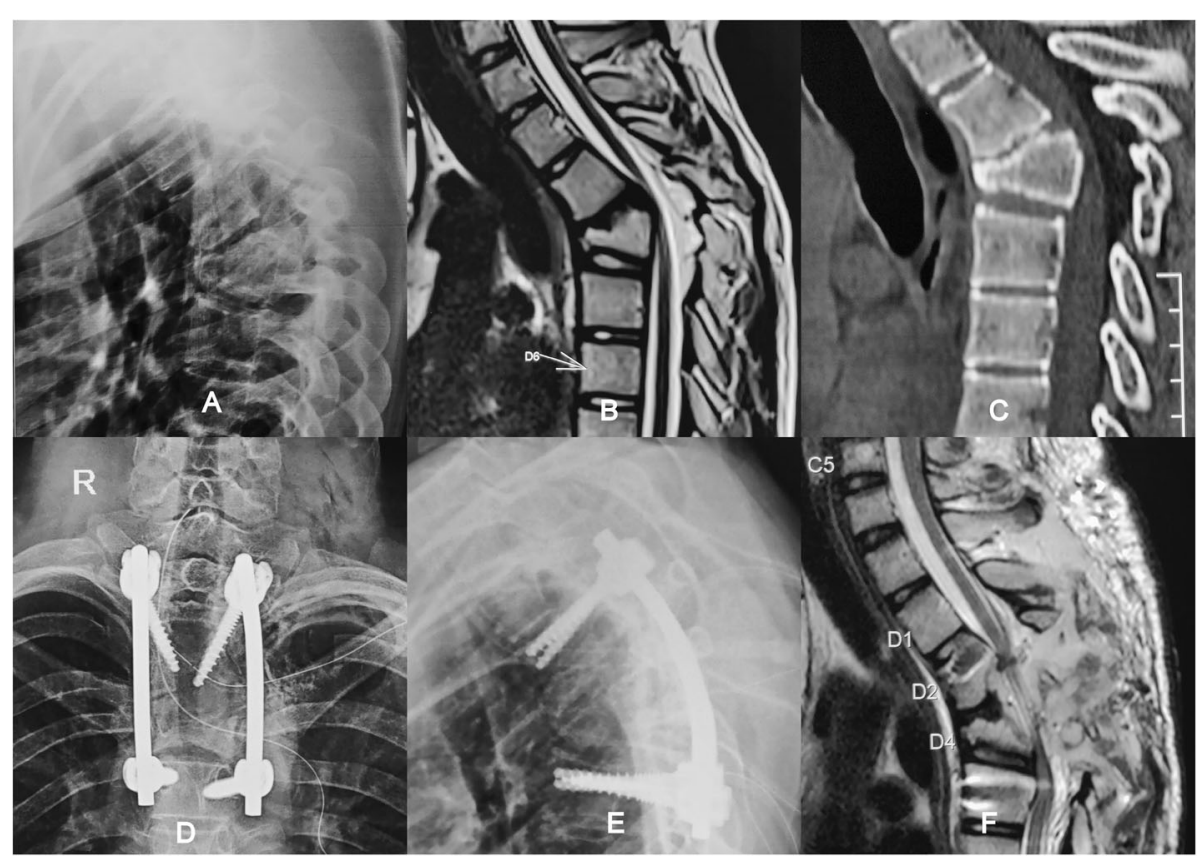

Fig. 1 Index case, 19-year-old male. a Preoperative lateral radiographs showing kyphosis. b, c Preoperative MRI T2-weighted sagittal image and preoperative CT scan sagittal section showing the kyphus with internal gibbus with block vertebra T3-4-5. d, e Postoperative anteroposterior and lateral radiographs showing single-segment screw fixation. f Postoperative MRI showing internal gibbectomy done and the decompressed cord. The preoperative status of neurology was mJOA (modified Japanese Orthopaedic Association) score 2; that improved to score 7 at 6 weeks. The duration of surgery was $275 \mathrm{~min}$ from induction to extubation. The hospital stay was 6 days. The total blood loss perioperative was $400 \mathrm{ml}$. Postoperative drain output of 3 days was $470 \mathrm{ml}$. 


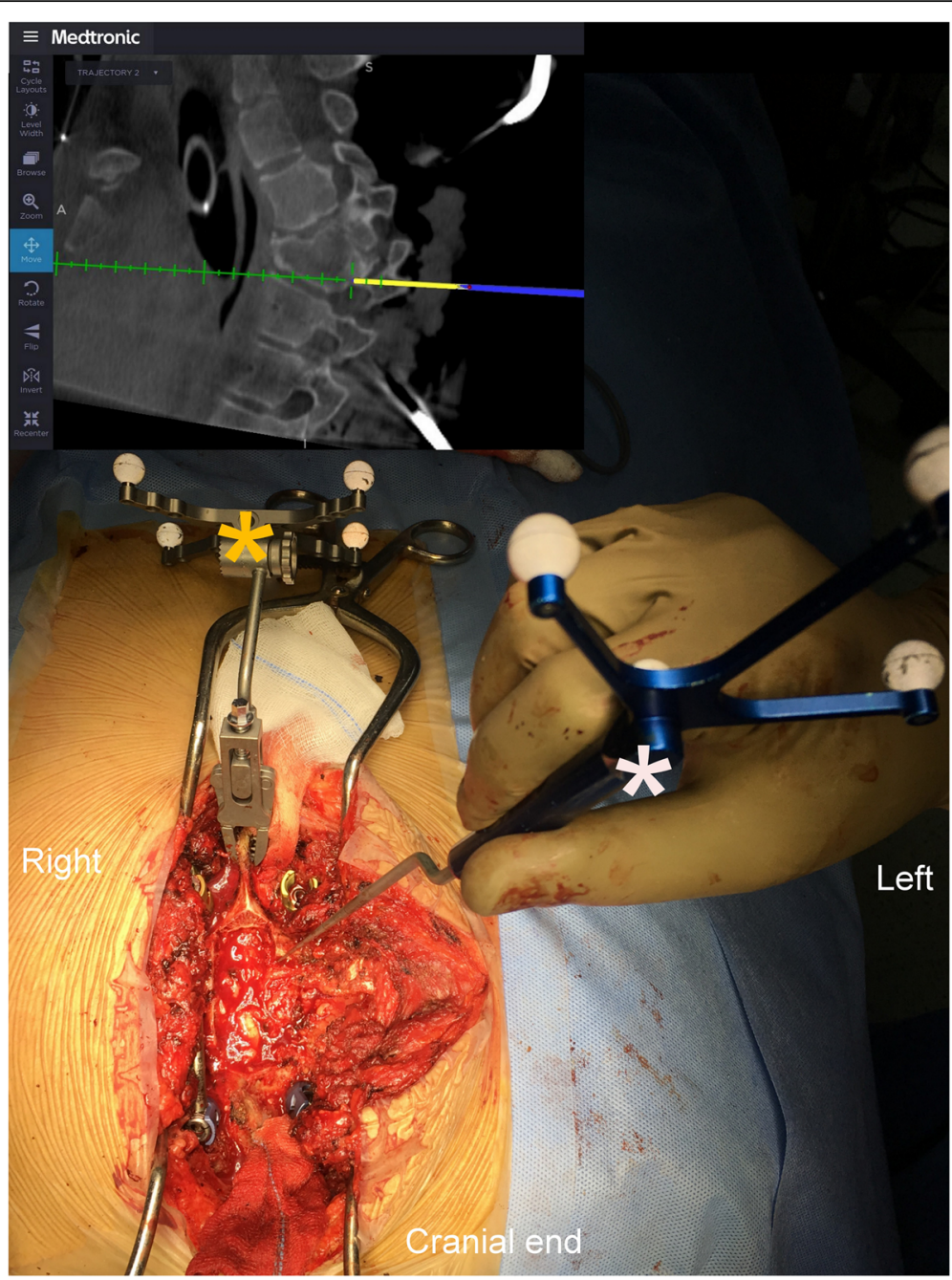

Fig. 2 Midline exposure with left lateral horizontal extension. Laminectomy was done with UBS. The rib, pedicle, and transverse processes were excised. Extra-cavitatory approach access ventrally achieved after roots sacrifices. Navigation probe (white asterisk) is being used to mark the extent of gibbus after clinical verification with Penfield probing. Navigation tracker placed caudally (yellow asterisk). Navigated probe being used (inset) to mark and confirm the extent of the planned gibbectomy

was extended up to the margins of pedicles. Using UBS with a 3rd-party navigation system mounted, a bone block was created by cutting postero-lateral one third of the vertebral body while leaving a slab still ventral to the cord. This was done at an approach angle of 5 to $20^{\circ}$ (Fig. 3). The block is completed throughout from the upper to lower extent of proposed decompression. The opposite side of the slab and block is cut vertically on the right side near the medial border of the pedicle (Fig. 4). The bone block ventral to the slab is now completely free and is pulled out laterally to create a trough space for the manipulation and delivery of the slab.

After making the trough, cranial and caudal defined margins are cut through bones with Misonix. If a disc is present, then it is cut with a knife. The cut through the posterior longitudinal ligament (PLL) is done with a knife at both ends (Fig. 5). This free ventral slab with PLL is manipulated with utmost care in the ventral direction and any adhesions dorsally with the cord are separated. The slab is now a flat sheet of the bone which is lying in the ventral trough space and is removed from the left side. The cord is now confirmed decompressed (Fig. 6). Also, after the completeness of the procedure, the Penfield dissector was used for the probing of ventral epidural space at the upper and lower angles of kyphosis which showed a completely relaxed lax cord. Moreover, a spherical appearance of the cord was regained on either side indicating an adequate endpoint.

\section{Bone grafting and reconstruction}

Cobalt-chromium rods were bilaterally fixed to the two screws on each side of the construct. The bed was 


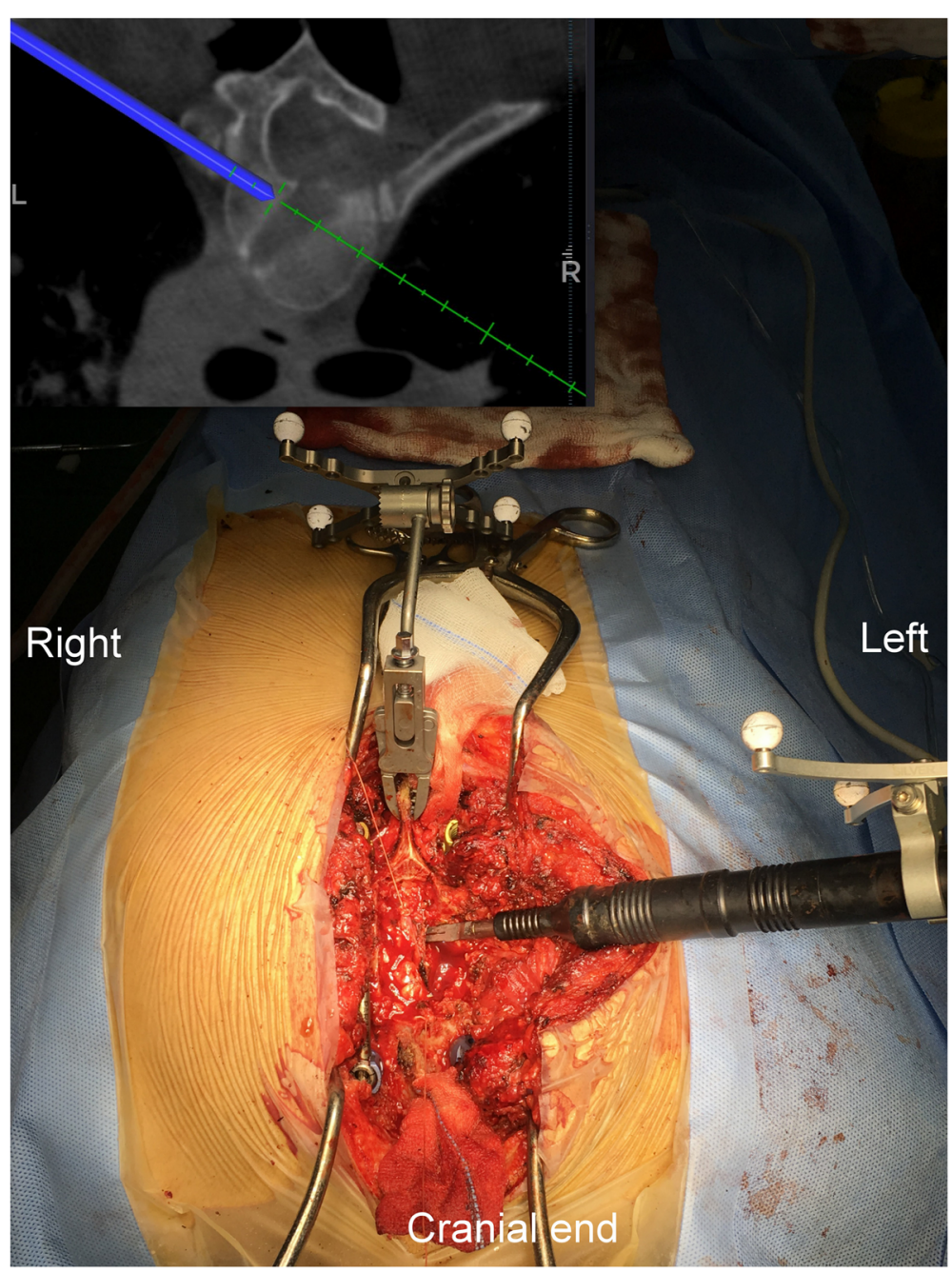

Fig. 3 Horizontal cut with UBS for creating trough space by cutting out the bone block. Virtual image showing navigated UBS is being used to cut out the bone block ventral to the cord and thin slab (inset)

prepared for bone grafting by shingling. On the left side, the bone graft extended from the proximal vertebra to the distal vertebra antero-laterally along the remaining shell of the osteotomised body. On the right side, facet joints and transverse processes bed were used (Fig. 7). Closure was done over two drains in layers.

\section{Discussion}

Ventral cord compression leading to thoracic myelopathy can be caused by conditions like congenital kyphosis, post infectious kyphosis, and calcified herniated discs, where surgical intervention is necessary $[1,2,15-$ 17].

The treatment of such conditions with only laminectomy is ineffective to decompress the cord because kyphosis restricts the backward shift of the cord. Anterior decompression by removal of the ossified ventral area may be the most effective method. However, an anterior approach only in an already compromised cord without laminectomy can invite severe complications. Moreover, with an anterior approach in severe kyphosis, visibility and orientation are difficult [18].

Staged anterior and posterior approaches have demonstrated favorable outcomes but increase patient morbidity by increasing surgical insult and time. Anterior plus posterior decompressions by posterior-only approaches are more versatile $[4-8,10,11,19-21]$.

The index case discussed is a late-presenting severe upper thoracic kyphosis with myelopathy. Current guidelines for kyphosis with myelopathy are of both anterior and posterior decompression and fusion, with dekyphosis $[4,5]$. In an older child, neurological injury is much more common $[9,22]$.

With increasing knowledge of osteotomies, surgeons have begun to develop techniques through posterioronly approaches $[4-7,23]$. Correction of greater Cobb 


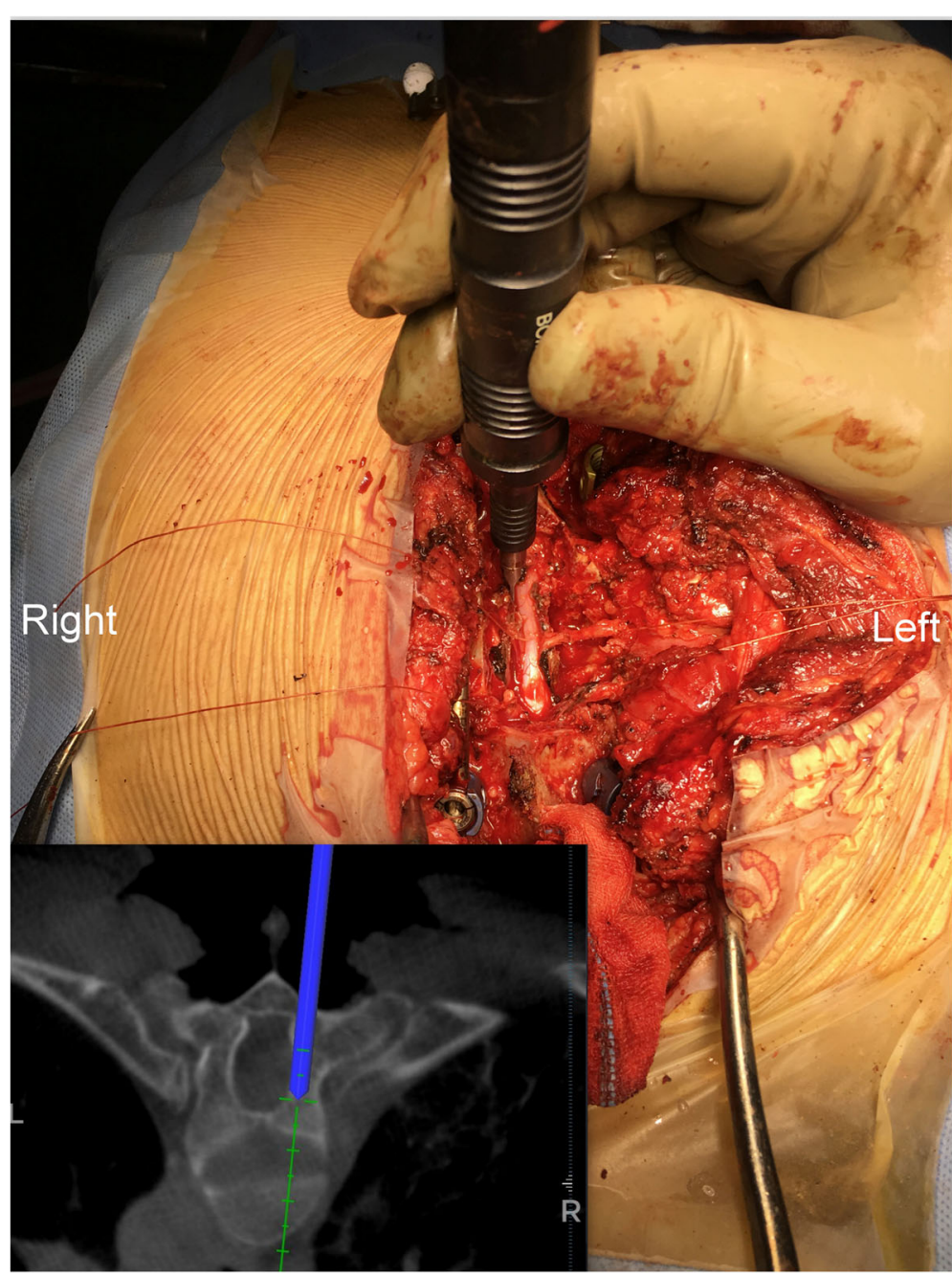

Fig. 4 Vertical cut being made on the opposite side to cut the bone block and slab ventral to the cord simultaneously. To be noted that after this cut the bone block is a free piece and the slab has still got distal and proximal attachments

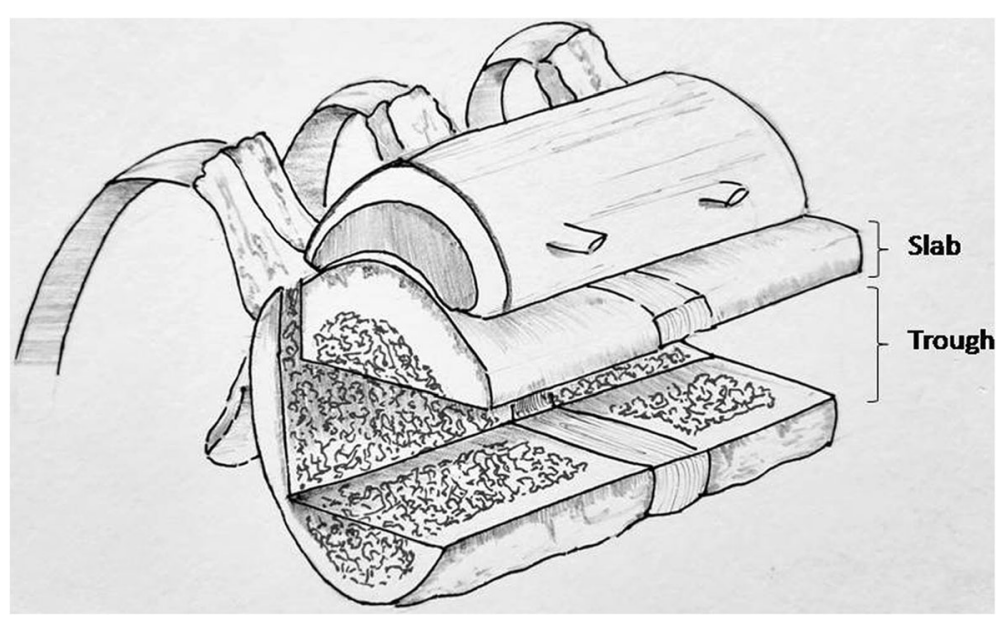

Fig. 5 Illustration showing that after the block is removed; the slab still presents ventral to the cord with adhesions 


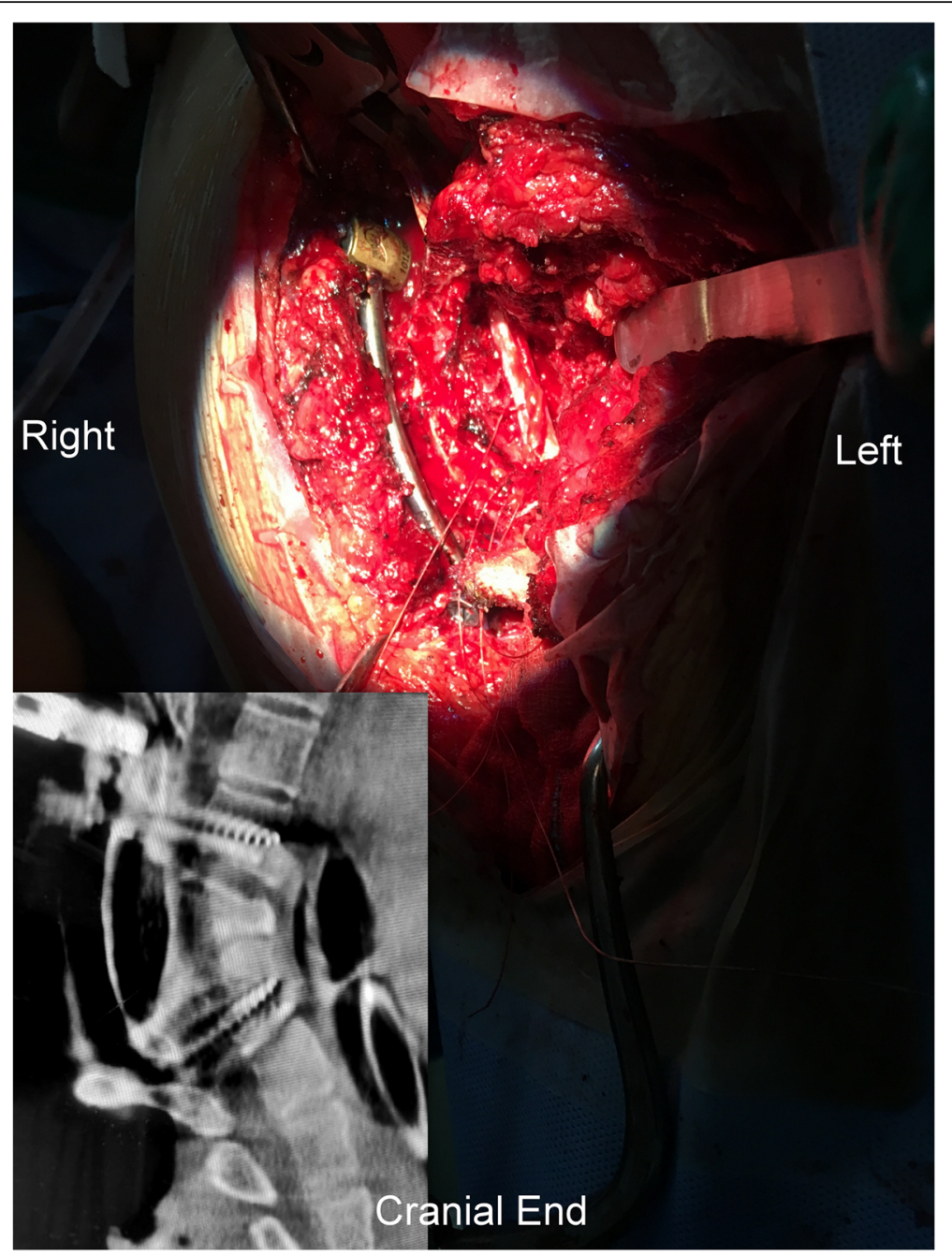

Fig. 6 The decompressed cord. After completion of osteotomy procedure, intraoperative O-arm acquired CT images confirming complete gibbectomy (inset)

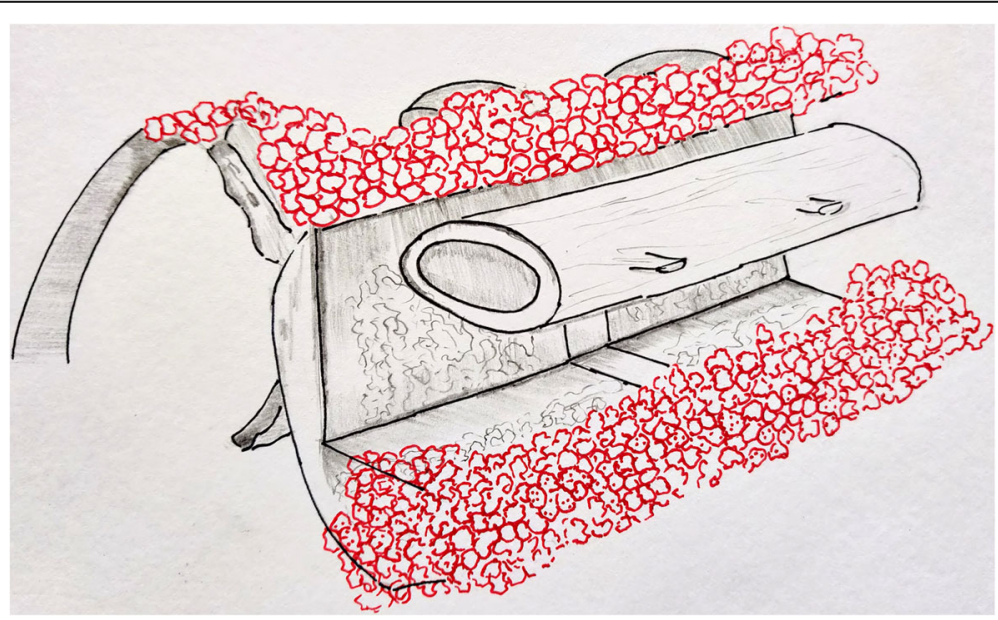

Fig. 7 Illustration showing $360^{\circ}$ decompressed cord with bone graft laid on bilateral sides on prepared beds 
angles requires a shortening of the spinal cord which is dangerous in an already compromised cord [9]. In evolving paraplegia, circumferential decompression is essential for neurologic recovery. Stability rather than correction is paramount. Song et al. [24] in their review of 52 patients who had surgical treatment for severe kyphosis, 17 patients had myelopathy. Anterior plus posterior decompression along with fusion without any attempted correction was observed to be a safer modality with better results than previously reported [24].

The conventional procedure for anterior decompression from a posterior approach was described by Ohtsuka et al. [10] where anterior ossification causing compression was cleared using a burr. Kato et al. [11] modified this technique by creating more space by removing transverse processes and pedicles with a reduction in neurological complications as further advantages.

UBS gives superiority in precise bone cuts and less bleeding. The UBS oscillates in a linear, piston-like motion enabling an effortless dissection of hard cortical bone. Less bleeding increases visibility and decreases the time consumed. Also, this not being a rotatory instrument is safer [12, 13].

Our approach is similar to that of the burr-using surgeries, but the opposite side cut is made without sacrificing the natural construct of facets completely. The UBS is put perpendicularly besides the pedicle levels after the roots are sacrificed. O-arm and navigation additionally increase the perfection of screws, predefining of osteotomy cuts and post decompression verification (Fig. 6) $[25,26]$. Preserving the one side of bony architecture helps to get additional bone graft bed and precise cuts prevent the instability. IONM is the current recommendation in most of the deformity and decompressive surgery mainly in the thoracic and cervical spine [27]. In high-end decompressive cases and kyphosis with neurological deficit, no signals may be elicitable from the start of the case itself. But routine cases of scoliosis or kyphosis surgery without any loss of signals or improvement of signals may be a positive recommendation for safe spine surgery. We also used IONM throughout the case. There were no signals in the lower limbs in supine preoperative pre-positioning, neither in prone position nor throughout the surgery. There were no signal improvements noted at the end and the patient woke up with the same preoperative neurological status.

There are limitations on the applicability of advanced technologies like $\mathrm{O}$-arm, navigation, and UBS due to cost. This is a technique report only and not a long-term data analysis. But this is applied in many cases of thoracic gibbus, OPLL, and calcified disc at the authors' institute with long-term outcomes awaited. Thus, this is a case report article and throws inputs to the technique of the procedure. This is going back in times and doing internal gibbectomy only as against the current recommendations but are less tedious than conventional vertebral column resection and correction. Moreover, adjunct technologies make the execution perfect. Postoperative CT scan has not been done to assess the status of laid bone graft on prepared beds. But the follow-up radiographs (Fig. 8) show the maintained alignment. No loss of reconstruction is indirect evidence of stability and fusion. Comparative analysis with kyphosis correction series on all parameters and variables are required to propose concrete recommendations. But with burr, this sculpting is nearly impossible or dangerous because

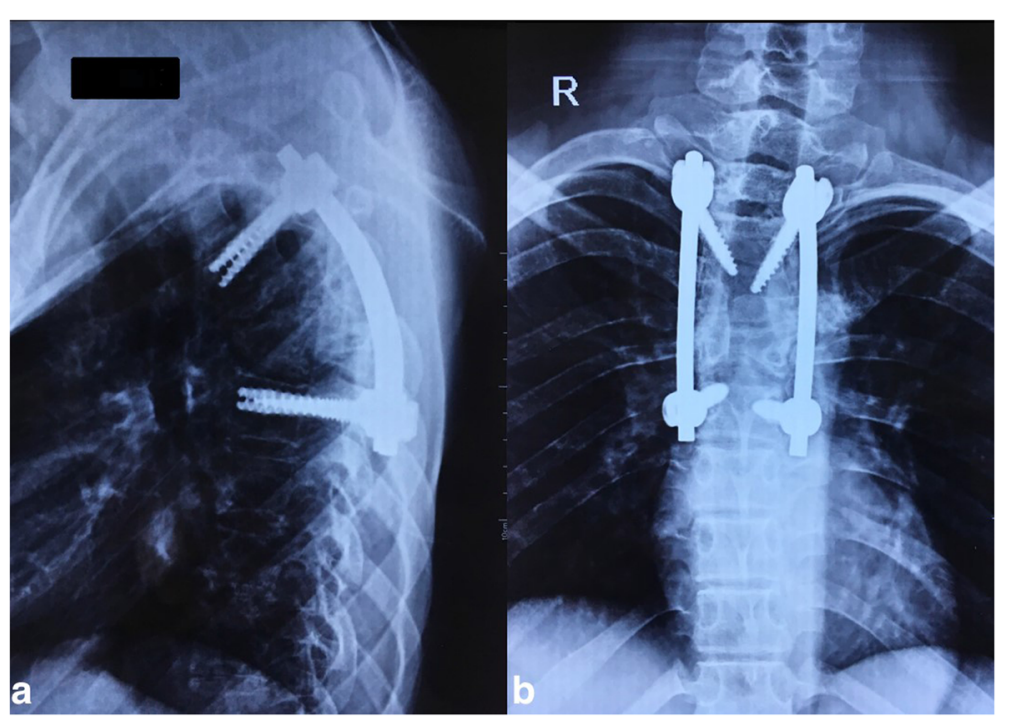

Fig. 8 Postoperative 27-month follow-up radiographs $(\mathbf{a}, \mathbf{b})$ showing maintenance of alignment, no loss of correction, or implant failure. The final mJOA score was 11 
of its rotating principle and limitations of working immediately adjoining the cord. It is quite evident that this technique with UBS does help in sculpting the decompression with the saving of time and blood without compromising stability. A significantly good bone-grafted bed for reinforcement union is available. Being single staged, it also reduces the surgical time and indirect cost required.

\section{Conclusions}

There are cost limitations to the applicability of advanced technologies like $\mathrm{O}$-arm, navigation, and UBS till the standard of care is laid down in health and insurance policies. This is a technique report which opens the future possibilities in many cases of thoracic gibbus, OPLL, and calcified disc. Though comparative analysis and long series are awaited, it is quite evident that this singlestage technique with UBS does help in sculpting tricky adequate ventral decompression.

\section{Abbreviations}

CSF: Cerebro-spinal fluid; CT: Computed tomography; IONM: Intraoperative neuromonitoring; OPLL: Ossified posterior longitudinal ligament; PLL: Posterior longitudinal ligament; UBS: Ultrasonic Bone Scalpel

\section{Acknowledgements}

I am thankful to Dr. Sameer Patil for his exemplary computer skills and drawings.

\section{Authors' contributions}

AK contributed as the chief operating surgeon and primary manuscript writer. SP contributed to image processing, primary manuscript writing, and computer work. CR and RR contributed to referencing work. SM and DD contributed to editing and proofreading. BD is the Director of the Institute. All authors read and approved the final manuscript.

\section{Funding}

Not applicable

\section{Availability of data and materials}

Not applicable

\section{Ethics approval and consent to participate}

Not applicable

\section{Consent for publication}

Written informed consent for the publication of the personal details and images that appear in this manuscript has been obtained from the participant.

\section{Competing interests}

The authors declare that they have no competing interests.

\section{Author details}

'Stavya Spine Hospital \& Research Institute, Nr Nagari Hospital, Mithakhali, Ellisbridge, Ahmedabad, Gujarat 380006, India. ${ }^{2}$ BIMS Hospital, Opp.Sir T Hospital, Charan Boarding, Jail Rd, Bhavnagar, Gujarat 364001, India.

${ }^{3}$ Ahmedabad, India.
Received: 7 January 2019 Accepted: 14 February 2020

Published online: 26 February 2020

\section{References}

1. Bozdogan E, Demir M, Konukoglu O, Karakas E. Reverse U-shaped horseshoe kidney accompanied by gibbus deformity and spina bifida. Jpn J Radiol. 2016:34(6):448-50

2. Weaver $P$, Lifeso RM. The radiological diagnosis of tuberculosis of the adult spine. Skeletal Radiol. 1984;12(3):178-86.

3. Ghandi M, Aycock RD, Berwald N, Hahn B. Gibbus deformity. J Emerg Med. 2015:49(3):340-1.

4. Shono Y, Abumi K, Kaneda K. One-stage posterior hemivertebra resection and correction using segmental posterior instrumentation. Spine. 2001;26(7): 752-7.

5. Shimode M, Kojima T. Sowa K. Spinal wedge osteotomy by a single posterior approach for correction of severe and rigid kyphosis or kyphoscoliosis Spine. 2002;27(20):2260-7.

6. Gertzbein SD, Harris MB. Wedge osteotomy for the correction of posttraumatic kyphosis: a new technique and a report of three cases. Spine. 1992:17(3):374-9.

7. Kawahara N, Tomita K, Baba H, Kobayashi T, Fujita T, Murakami H. Closingopening wedge osteotomy to correct angular kyphotic deformity by a single posterior approach. Spine. 2001;26(4):391-402

8. Rajasekaran S, Vijay K, Shetty AP. Single-stage closing-opening wedge osteotomy of spine to correct severe post-tubercular kyphotic deformities of the spine: a 3-year follow-up of 17 patients. Eur Spine J. 2010;19(4):583-92.

9. Noordeen $\mathrm{MH}$, Garrido E, Tucker SK, Elsebaie HB. The surgical treatment of congenital kyphosis. Spine. 2009;34(17):1808-14

10. Ohtsuka K, Terayama K, Tsuchiya T, Wada K, Furukawa K, Ohkubo M. A surgical procedure of the anterior decompression of the thoracic spinal cord through the posterior approach. Orthop Surg Traumatol. 1983;26: $1083-90$

11. Kato S, Murakami H, Demura S, Yoshioka K, Hayashi H, Tsuchiya H. Novel surgical technique for ossification of posterior longitudinal ligament in the thoracic spine. J Neurosurg Spine. 2012;17(6):525-9.

12. Sanborn MR, Balzer J, Gerszten PC, Karausky P, Cheng BC, Welch WC. Safety and efficacy of a novel ultrasonic osteotome device in an ovine model. J Clin Neurosci. 2011;18(11):1528-33.

13. Dave BR, Degulmadi D, Dahibhate S, Krishnan A, Patel D. Ultrasonic bone scalpel: utility in cervical corpectomy. A technical note. Eur Spine J. 2018; $14 \cdot 1-6$

14. Hu X, Ohnmeiss DD, Lieberman $\|_{\text {. }}$. Use of an ultrasonic osteotome device in spine surgery: experience from the first 128 patients. Eur Spine J. 2013; 22(12):2845-9.

15. Barbanera A, Serchi E, Fiorenza V, Nina P, Andreoli A. Giant calcified thoracic herniated disc: considerations aiming a proper surgical strategy. J Neurosurg Sci. 2009:53:19-25 discussion 25-6.

16. Matsumoto M, Chiba K, Toyama Y, Takeshita K, Seichi A, Nakamura K, et al. Surgical results and related factors for ossification of posterior longitudinal ligament of the thoracic spine: a multi-institutional retrospective study. Spine. 2008;33:1034-41.

17. Yamazaki M, Okawa A, Mannoji C, Fujiyoshi T, Furuya T, Koda M. Postoperative paralysis following posterior decompression with instrumented fusion for thoracic myelopathy caused by ossification of the posterior longitudinal ligament. J Clin Neurosci. 18:294-6.

18. Ma X, An HS, Zhang Y, Brown NM, Chen Z, Zhang G, et al. A radical procedure of circumferential spinal cord decompression through a modified posterior approach for thoracic myelopathy caused by severely impinging anterior ossification. Spine J. 2014;14(4):651-8.

19. Yang C, Bi Z, Fu C, Zhang Z. A modified decompression surgery for thoracic myelopathy caused by ossification of posterior longitudinal ligament: a case report and literature review. Spine. 2010;35(13):E609-13.

20. Takahata M, Ito M, Abumi K, Kotani Y, Sudo H, Minami A. Clinical results and complications of circumferential spinal cord decompression through a single posterior approach for thoracic myelopathy caused by ossification of posterior longitudinal ligament. Spine. 2008;33(11):1199-208.

21. Dalal S, Modi J, Soman S, Patel H, Dhanani S. Results of single-staged posterior decompression and circumferential fusion using a transpedicular approach to correct a kyphotic deformity due to thoracolumbar spinal tuberculosis. Asian spine J. 2016;10(6):1106-14. 
22. McMaster MJ, Singh H. The surgical management of congenital kyphosis and kyphoscoliosis. Spine. 2001;26(19):2146-54.

23. Srivastava SK, Aggarwal RA, Bhosale SK, Roy K, Nemade PS. The versatile approach: a novel single incision combined with anterior and posterior approaches for decompression and instrumented fusion to treat tuberculosis of the thoracic spine. Asian Spine J. 2017;11(2):294-304

24. Song KS, Chang BS, Yeom JS, Lee JH, Park KW, Lee CK. Surgical treatment of severe angular kyphosis with myelopathy: anterior and posterior approach with pedicle screw instrumentation. Spine. 2008;33:1229-35.

25. Kotani T, Akazawa T, Sakuma T, Koyama K, Nemoto T, Nawata K, et al. Accuracy of pedicle screw placement in scoliosis surgery: a comparison between conventional computed tomography-based and O-arm-based navigation techniques. Asian Spine J. 2014;8(3):331-8.

26. Kobayashi K, Imagama S, Ito Z, Ando K, Yokoi K, Ishiguro N. Utility of a computed tomography-based navigation system (O-Arm) for en bloc partial vertebrectomy for lung cancer adjacent to the thoracic spine: technical case report. Asian Spine J. 2016;10(2):360-5.

27. Sestokas AK, Tesdahl EA, Harrop JS, Vaccaro AR, Wallace BA, Wilent WB, Martin EM, Cohen J. Neurologic complications may occur during any stage of extradural spine surgery: intraoperative neuromonitoring findings and outcomes in 107,447 procedures. Spine Journal. 2017;17(10):S203.

\section{Publisher's Note}

Springer Nature remains neutral with regard to jurisdictional claims in published maps and institutional affiliations.

\section{Submit your manuscript to a SpringerOpen ${ }^{\circ}$ journal and benefit from:}

- Convenient online submission

- Rigorous peer review

- Open access: articles freely available online

- High visibility within the field

- Retaining the copyright to your article

Submit your next manuscript at $\boldsymbol{\nabla}$ springeropen.com 